\title{
OPTIMAL DISIGN OF ENERGY SUPPLY NETS ON GRAPHS
}

\author{
Vladimir Nikulshin ${ }^{1)}$, Viktoria von Zedtwitz ${ }^{2)}$ \\ 1) Professor and Head of Department, Odessa National Polytechnic Univ., Ukraine, \\ Phone: +38 0487797 416; +38 0487797233 Fax: +38 0482250104 \\ e-mail:vnikul@paco.odessa.ua \\ ${ }^{2)}$ M.Sc, PhD Student, ETH, Zurich, Switzerland
}

\begin{abstract}
In the design and operation of energy intensive systems, the possibility of improving the system's efficiency is very important to explore. The main way of improving efficiency is through optimisation. This paper describes the application of exergy topological models and, in particular, the graph of thermoeconomical expenditure for thermoeconomical optimal design s of circled nets for energy supply (CNES). The questions of thermoeconomical optimisation of CNES, as well as suggested modelling algorithms, are illustrated in the numerical example of the optimisation of a energy supply system for a city with seven regions of energy consumption.
\end{abstract}

Keywords: Optimal design, energy supply nets, thermoeconomic.

\section{INTRODUCTION}

The processes taking place in complex energy intensive systems are characterized by the mutual transformation of quantitatively different power resources. The thermo-economical optimisation of CNES is based on thermodynamic analysis, which requires the combined application of both laws of thermodynamics and demands the exergy approach ([1], [2]).

Exergetic methods are universal and make it possible to estimate the fluxes and balances of energy for every element of the system using a common criterion of efficiency.

Therefore, the exergetic methods are meaningful in analysis and calculations.

Meanwhile, the increasing complexity of optimisation problems requires more effective and powerful mathematical methods. Therefore, during the last few years, many papers with different applications of exergetic methods and the thermoeconomical approach have been published (see for example [3], [4], [5], [7]).

The above referenced papers, as well as the author's past investigations [7-12], show that one of the most effective mathematical methods used for exergetic analysis and thermoeconomical optimisation involve graph theory [13]. The usefulness of graph models can also be demonstrated by their flexibility and wide range of possible applications.
The exergy topological method includes the sole use or combination of exergy flow graphs [7-9] and thermoeconomical graphs [10-12].This paper describes the application of exergy topological models and, in particular, the graph of thermoeconomical expenditure for thermoeconomical optimisation of CNES.

\section{METHOD AND ALGORITHM OF OPTIMAL SYNTHESIS OF CNES}

Let's assume that the CNES contains m customers and the possible methods of connection of these customers by a net are known.

Then, for this CNES, in accordance with rules given in [11,12], the graph of thermoeconomical expenditure can be built. Shown in Fig. 1 is a graph whose nodes multitude $\mathrm{A}=\left\{\mathrm{a}_{1}, \mathrm{a}_{2}, \ldots, \mathrm{a}_{\mathrm{i}}, \ldots, \mathrm{a}_{\mathrm{m}}\right\}$ corresponds to the customers and arcs multitude $\mathrm{U}=\left\{\mathrm{a}_{\mathrm{i}}, \mathrm{a}_{\mathrm{j}}\right\} ; \mathrm{i} \neq \mathrm{j} ; \mathrm{i}=1,2, \ldots, \mathrm{m} ; \mathrm{j}=1,2, \ldots, \mathrm{m}$; to the appropriate parts of CNES between nodes $a_{i}, a_{j}$. Each arc $\mathrm{U}_{\mathrm{ij}}$ has thermoeconomical expenditure $\mathrm{Z}_{\mathrm{ij}}$ as it is shown in the matrix of thermoeconomical expenditure (see Fig. 2.) and the graph in Fig. 1.

Then, by minimizing the sum shown in Eq. (1), the problem of optimal thermoeconomical synthesis can be solved.

$$
Z_{\Sigma}^{\min }=\min \sum_{i} \sum_{j} Z_{i j}
$$




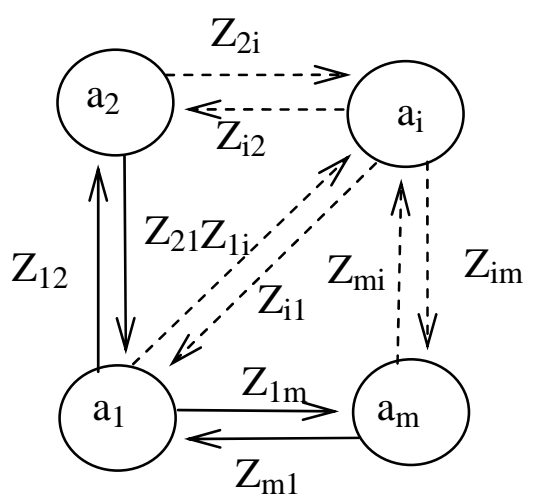

Fig.1 - Graph of thermoeconomical expenditure.

\begin{tabular}{|c|c|c|c|c|c|c|}
\hline & $\mathbf{a}_{1}$ & $\mathbf{a}_{2}$ & $\ldots$ & $\mathbf{a}_{\mathbf{j}}$ & $\ldots$ & $\mathbf{a}_{\mathbf{m}}$ \\
\hline $\mathbf{a}_{1}$ & $\mathbf{Z}_{11}$ & $Z_{12}$ & & $\mathbf{Z}_{1 \mathbf{j}}$ & & $\mathbf{Z}_{1 \mathrm{~m}}$ \\
\hline $\mathbf{a}_{2}$ & $Z_{21}$ & $\mathbf{Z}_{22}$ & & $\mathbf{Z}_{2 \mathbf{j}}$ & & $\mathbf{Z}_{2 \mathrm{~m}}$ \\
\hline 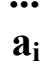 & $Z_{i 1}$ & $Z_{i 2}$ & & $\mathbf{Z}_{\mathrm{ij}}$ & & $\mathbf{Z}_{\mathrm{im}}$ \\
\hline & $\mathbf{Z}_{\mathrm{m}}$ & $Z_{m}$ & & $Z_{m i}$ & & $Z_{m m}$ \\
\hline & & & $\cdots$ & $\mathbf{Z}_{\mathbf{m j}}$ & $\cdots$ & $Z_{\mathrm{mm}}$ \\
\hline
\end{tabular}

Fig.2 - Matrix of thermoeconomical expenditure corresponding to a graph in Fig.1.

Given below is the matrix form of a special algorithm for the optimal synthesis of CNES based on the finding of a Hamilton contour [13] in the graph of thermoeconomical expenditure

$\mathrm{Z}_{\mathrm{U}}=(\mathrm{A}, \mathrm{U})$.

The algorithm consists of following main steps:

Step 1. Calculate the possible thermoeconomical expenditure $\mathrm{Z}_{\mathrm{ij}}=\mathrm{Z}\left(\mathrm{a}_{\mathrm{i}}, \mathrm{a}_{\mathrm{j}}\right), \forall \mathrm{a}_{\mathrm{i}} \in \mathrm{A}$,

$\forall \mathrm{a}_{\mathrm{j}} \in \mathrm{A}$ and form a square matrix of size $\mathbf{m} \mathbf{x} \mathbf{~ m}$ for the thermoeconomical expenditure (See Fig.2.).

Step 2. Find a minimum element in each i-th line of the matrix $Z_{i}^{\min }=\min \left\{Z_{i j}\right\}, j=1,2 \ldots, m ; i=1,2 \ldots$, $m$ and subtract the element from all elements in this line.

Step 3. Check: are there any matrix columns that do not include zero elements?

If yes, then go to step 4 .

If not, then each line and each column contain at least one zero member. Proceed to step 5.

Step 4. Find, in each j- column, that does not include the zero elements, a minimum element. This element will be $Z_{j}^{\min }=\min \left\{Z_{i j}\right\}, i=1,2 \ldots, m ; j=$ $1,2 \ldots, m$. Now subtract $Z_{j}^{\text {min }}$ from all elements of this column. The result will be an inclusive matrix yielding one zero element in each column and each line.
Step 5. Calculate the sum: $Z_{\Sigma}^{0}=\sum_{i} Z_{i}^{\text {min }}$ $+\sum_{\mathrm{j}} \mathrm{Z}_{\mathrm{j}}^{\min }$

This sum, $Z_{\Sigma}{ }^{0}$, is the lower boundary of a set of the solutions and can be accepted as the root tree for the thermoeconomical expenditure.

It is understandable that if step 4 was not executed, then $\mathrm{Z}_{\mathrm{j}}^{\mathrm{min}}=0$.

Step 6. Select an arc, $\left(a_{k}, a_{1}\right)$, for which

$$
\mathrm{R}^{\max }\left(\mathrm{a}_{\mathrm{k}}, \mathrm{a}_{\mathrm{l}}\right)=\max \left\{\mathrm{R}\left(\mathrm{a}_{\mathrm{i}}, \mathrm{a}_{\mathrm{j}}\right)\right\}
$$

$R\left(a_{i}, a_{j}\right)$ - the sum of the least element of $i$-th line and $\mathrm{j}$-th column of a matrix. Zero element is located is the interception of these i-th line and $j$-th column.

Step 7. Find, in the tree of thermo-economical expenditure, a dangling vertex with the least boundary.

Step 8. Form the new vertex with a boundary equal the sum of the boundary of vertex in step 7 with value $\mathrm{R}^{\max }\left(\mathrm{a}_{\mathrm{k}}, \mathrm{a}_{\mathrm{l}}\right)$.

An adequate contour for this vertex will not use an $\operatorname{arc}\left(\mathrm{a}_{\mathrm{k}}, \mathrm{a}_{\mathrm{l}}\right)$.

Let's designate this property through $\bar{S}_{k l}$.

Step 9. Eliminate the k-th line and l-th column in the matrix corresponding to an element $\mathrm{R}^{\max }\left(\mathrm{a}_{\mathrm{k}}, \mathrm{a}_{\mathrm{l}}\right)$. Then the size of the matrix will decrease by a unit.

Step 10. Exchange a symbol, $\infty$, for the thermoeconomical expenditure of arcs, which permits finding contours of length smaller than the m-size.

Step 11. Check: Is the size of the matrix obtained in step 10 more than that of a unit?

If yes, then go to a step 12 .

If not, then go to a step 19.

Steps 12, 13, 14, and 15 repeat steps 2, 3, 4, and 5 , but these calculations are done with the matrix obtained in step 10 (instead of the initial matrix used in previously).

Step 16. Add the sum obtained in step 15 to the value for the boundary of vertex from which one splitting was done (in the first step, this is the boundary for a root tree of thermoeconomical expenditure).

The final result will be the boundary for the new dangling vertex - a contour will use an arc $\left(a_{k}, a_{l}\right)$ that is adequate for the condition in step 6 .

Step 17. Find the dangling vertex with the least boundary. If there are only a few dangling vertices with the same boundaries, then select a vertex that is characterized by property $S_{\mathrm{kl}}$. This step is essential in order to find arcs that are included in a Hamilton contour. 
Step 18. Check: is the vertex found in step 17 built by applying the property $\bar{S}_{k l}$ ?

If yes, then go to a step 6 .

If is not, then go to a step 9.

Step 19. The problem is solved - optimal pairs of elements (customers) $a_{i}$ and $a_{j}$ are found that correspond to the appropriate vertex sequence. By starting from the root tree and finishing with the dangling vertex for a matrix of unit size, the single contour CNES, with the minimum thermoeconomical expenditure in accordance with Eq. 1, can be determined.

\section{NUMERICAL EXAMPLE OF OPTIMAL SYNTHESIS OF SINGLE CONTOUR CNES}

Let's consider a problem of an optimal synthesis, single contour CNES for a city with seven regions of energy consumption (see scheme in Fig. 3.).

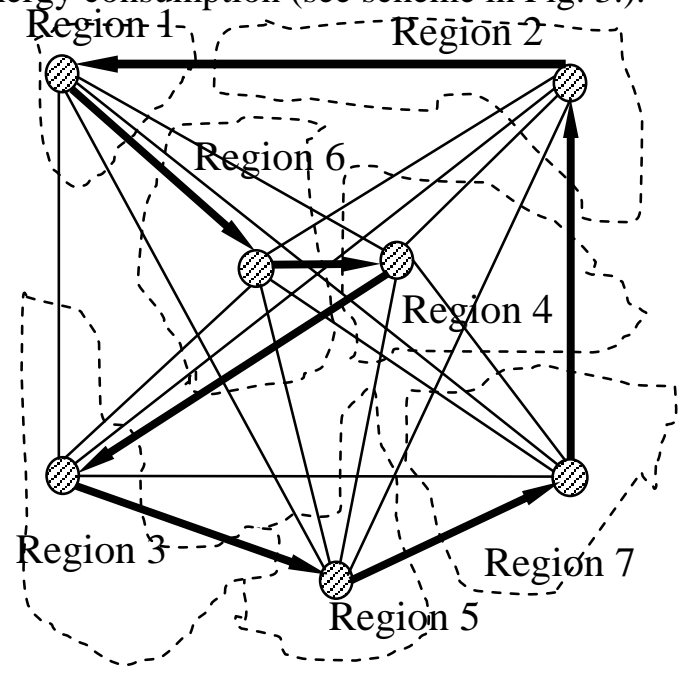

Fig.3 - Scheme CNES with seven region of energy consumption

The graph of thermoeconomical expenditure is given in Fig. 4, and the matrix of thermoeconomical expenditure, $\mathbf{M}_{\mathbf{1}}$, is found in Fig. 5 .

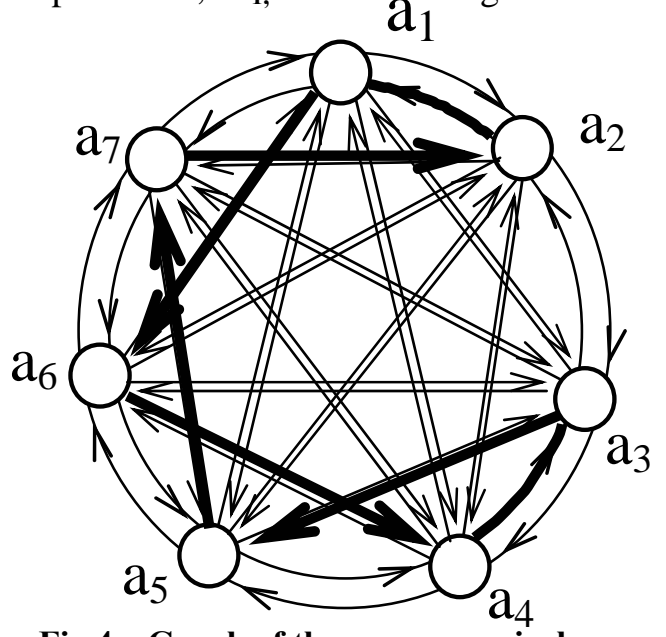

Fig.4 - Graph of thermoeconomical expenditure for scheme in Fig.3.

\begin{tabular}{|c|c|c|c|c|c|c|c|}
\hline & $\mathrm{a}_{1}$ & $\mathrm{a}_{2}$ & $\mathrm{a}_{3}$ & $a_{4}$ & $a_{5}$ & $a_{6}$ & $a_{7}$ \\
\hline$a_{1}$ & $\infty$ & 1050 & 1850 & 1200 & 6300 & 1100 & 1900 \\
\hline$a_{2}$ & 1050 & $\infty$ & 1700 & 1600 & 900 & 2500 & 400 \\
\hline$a_{3}$ & 1850 & 1700 & $\infty$ & 200 & 1200 & 1550 & 1500 \\
\hline$a_{4}$ & 1200 & 1600 & 200 & $\infty$ & 400 & 800 & 900 \\
\hline$a_{5}$ & 6300 & 900 & 1200 & 400 & $\infty$ & 300 & 450 \\
\hline $\mathrm{a}_{6}$ & 1100 & 2500 & 1550 & 800 & 300 & $\infty$ & 950 \\
\hline$a_{7}$ & 1900 & 400 & 1500 & 900 & 450 & 950 & $\infty$ \\
\hline
\end{tabular}

\begin{tabular}{|c|c|c|c|c|c|c|c|}
\hline & $a_{1}$ & $\mathrm{a}_{2}$ & $a_{3}$ & $a_{4}$ & $a_{5}$ & $a_{6}$ & $a_{7}$ \\
\hline$a_{1}$ & $\infty$ & 0 & 800 & 150 & 5250 & 50 & 850 \\
\hline$a_{2}$ & 750 & $\infty$ & 1300 & 1200 & 500 & 2100 & $\mathbf{0}$ \\
\hline$a_{3}$ & 1650 & 1500 & $\infty$ & $\mathbf{0}$ & 100 & 1350 & 1300 \\
\hline$a_{4}$ & 100 & 1400 & $\mathbf{0}$ & $\infty$ & 200 & 600 & 700 \\
\hline$a_{5}$ & 6000 & 600 & 900 & 100 & $\infty$ & 0 & 150 \\
\hline $\mathrm{a}_{6}$ & 800 & 2200 & 1250 & 500 & $\mathbf{0}$ & $\infty$ & 650 \\
\hline$a_{7}$ & 1500 & 0 & 1300 & 500 & 50 & $\begin{array}{l}550 \\
\end{array}$ & $\infty$ \\
\hline
\end{tabular}

\begin{tabular}{|c|c|c|c|c|c|c|c|}
\hline & $\mathrm{a}_{1}$ & $a_{2}$ & $a_{3}$ & $\mathrm{a}_{4}$ & $a_{5}$ & $\mathrm{a}_{6}$ & $\mathrm{a}_{7}$ \\
\hline$a_{1}$ & $\infty$ & $\mathbf{0}$ & 800 & 150 & 5250 & 50 & 850 \\
\hline$a_{2}$ & 650 & $\infty$ & 1300 & 1200 & 500 & 2100 & 0 \\
\hline$a_{3}$ & 1550 & 1500 & $\infty$ & 0 & 100 & 1350 & 1300 \\
\hline$a_{4}$ & 100 & 1400 & $\mathbf{0}$ & $\infty$ & 200 & 600 & 700 \\
\hline$a_{5}$ & 5900 & 600 & 900 & 100 & $\infty$ & 0 & 150 \\
\hline$a_{6}$ & 700 & 2200 & 1250 & 500 & $\mathbf{0}$ & $\infty$ & 650 \\
\hline$a_{7}$ & 1400 & 0 & 1300 & 500 & 50 & $\mathbf{5 5 0}$ & $\infty$ \\
\hline
\end{tabular}

Fig.5 - Matrixes of thermoeconomical expenditures

$$
\mathbf{M}_{1}-\mathbf{M}_{3} \text {. }
$$

The matrices of solution, $\mathbf{M}_{1}-\mathbf{M}_{23}$ (see Fig. 5Fig. 9), as well as the tree of thermoeconomical expenditure (see Fig. 10), are obtained as a result of applying the suggested algorithm.

It is easy to see that the optimal single contour CNES (in Fig. 4 and Fig. 5 - designated by bold lines) contains the appropriate sequence of nodes (customers): $\left(\mathrm{a}_{1}, \mathrm{a}_{6}, \mathrm{a}_{4}, \mathrm{a}_{3}, \mathrm{a}_{5}, \mathrm{a}_{7}, \mathrm{a}_{2}, \mathrm{a}_{1}\right)$.

The minimum thermoeconomical expenditure for this optimized CNES is 4400 .

\begin{tabular}{|c|c|c|c|c|c|c|}
\hline & $\mathrm{a}_{1}$ & $a_{2}$ & $\mathrm{a}_{4}$ & $\mathrm{a}_{5}$ & $\mathrm{a}_{6}$ & $\mathrm{a}_{7}$ \\
\hline $\mathrm{a}$ & $\infty$ & $\overline{0}$ & 150 & 5250 & 50 & 850 \\
\hline $\mathrm{a}$ & 650 & $\infty$ & 1200 & 500 & 2100 & $\mathbf{0}$ \\
\hline d & 1550 & 1500 & $\infty$ & 100 & 1350 & 1300 \\
\hline $\mathrm{a}$ & 5900 & 600 & 100 & $\infty$ & $\mathbf{0}$ & 150 \\
\hline $\mathrm{a}_{6}$ & 700 & 2200 & 500 & 0 & $\infty$ & 650 \\
\hline $\mathrm{a}$ & 1400 & $\mathbf{0}$ & 500 & 50 & 550 & $\infty$ \\
\hline
\end{tabular}




\begin{tabular}{|c|c|c|c|c|c|c|}
\hline & $a_{1}$ & $\mathrm{a}_{2}$ & $a_{4}$ & $a_{5}$ & $a_{6}$ & $a_{7}$ \\
\hline & $\infty$ & $\mathbf{0}$ & 150 & 5250 & 50 & 850 \\
\hline $\mathrm{a}$ & 650 & $\infty$ & 1200 & 500 & 2100 & $\mathbf{0}$ \\
\hline$a$ & 1450 & 1400 & $\infty$ & 0 & 1250 & 1200 \\
\hline a & 5900 & 600 & 100 & $\infty$ & 0 & 150 \\
\hline$a_{6}$ & 700 & 2200 & 500 & 0 & $\infty$ & 650 \\
\hline $\mathbf{u}$ & 1400 & 0 & 500 & 50 & 550 & $\infty$ \\
\hline
\end{tabular}

\begin{tabular}{|c|c|c|c|c|c|c|}
\hline & $a_{1}$ & $a_{2}$ & $a_{4}$ & $a_{5}$ & $a_{6}$ & $\mathrm{a}_{7}$ \\
\hline$a_{1}$ & $\infty$ & $\mathbf{0}$ & 50 & 5250 & 50 & 850 \\
\hline$a_{2}$ & 0 & $\infty$ & 1100 & 500 & 2100 & 0 \\
\hline$a_{3}$ & 800 & 1400 & $\infty$ & 0 & 1250 & 1200 \\
\hline$a_{5}$ & 5250 & 600 & 0 & $\infty$ & 0 & 150 \\
\hline$a_{6}$ & 50 & 2200 & 400 & 0 & $\infty$ & 650 \\
\hline$a_{7}$ & 750 & 0 & 400 & 50 & $\mathbf{5 5 0}$ & $\infty$ \\
\hline
\end{tabular}

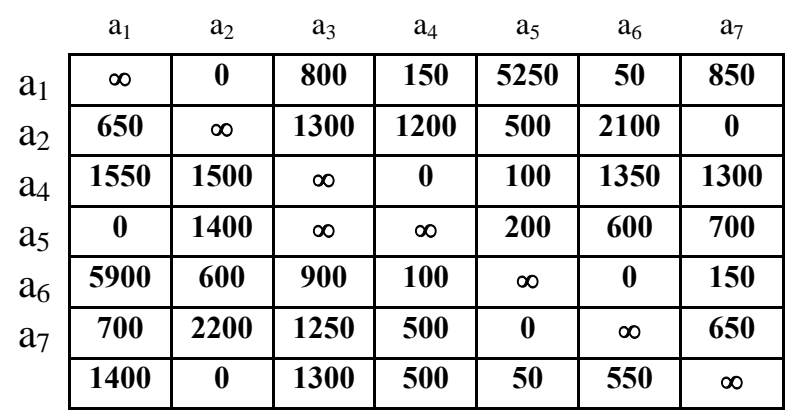

Fig.6 - Matrixes of thermoeconomical expenditures $\mathbf{M}_{\mathbf{4}}-\mathbf{M}_{7}$

\begin{tabular}{|c|c|c|c|c|c|c|c|}
\hline & $a_{1}$ & & $a_{3}$ & $a_{4}$ & $a_{5}$ & $a_{6}$ & $a_{7}$ \\
\hline $\mathrm{a}_{1}$ & $\infty$ & 0 & 0 & 150 & 5250 & 50 & $\mathbf{8 5 0}$ \\
\hline $\mathrm{a}_{2}$ & 650 & $\infty$ & 500 & 1200 & 500 & 2100 & 0 \\
\hline$a_{3}$ & 1550 & 1500 & $\infty$ & 0 & 100 & 1350 & 1300 \\
\hline $\mathrm{a}_{4}$ & 0 & 1400 & $\infty$ & $\infty$ & 200 & 600 & 700 \\
\hline $\mathrm{a}_{5}$ & 5900 & 600 & 100 & 100 & $\infty$ & 0 & 150 \\
\hline $\mathrm{a}_{6}$ & 700 & 2200 & 450 & 500 & 0 & $\infty$ & 650 \\
\hline $\mathrm{a}_{7}$ & 1400 & 0 & 500 & 500 & 50 & 550 & $\infty$ \\
\hline
\end{tabular}

\begin{tabular}{|c|c|c|c|c|c|c|}
\hline & $\mathrm{a}_{2}$ & $a_{3}$ & $\mathrm{a}_{4}$ & $a_{5}$ & $\mathrm{a}_{6}$ & $a_{7}$ \\
\hline $\mathrm{a}_{1}$ & $\mathbf{0}$ & $\overline{0}$ & $\propto$ & 5250 & 50 & 850 \\
\hline a & $\infty$ & 500 & 1200 & 500 & 2100 & $\mathbf{0}$ \\
\hline a & 1500 & $\infty$ & $\mathbf{0}$ & 100 & 1350 & 1300 \\
\hline$a_{5}$ & 600 & 100 & 100 & $\infty$ & 0 & 150 \\
\hline $\mathrm{a}_{6}$ & 2200 & 450 & 500 & $\mathbf{0}$ & $\infty$ & 650 \\
\hline $\mathrm{a}$ & 0 & 500 & 500 & 50 & 550 & $\infty$ \\
\hline
\end{tabular}

\begin{tabular}{|c|c|c|c|c|c|}
\hline & $a_{2}$ & $a_{3}$ & $\mathrm{a}_{4}$ & $a_{5}$ & $\mathrm{a}_{6}$ \\
\hline$a_{1}$ & $\mathbf{0}$ & $\mathbf{0}$ & $\propto$ & 5250 & 50 \\
\hline$a_{3}$ & 1500 & $\infty$ & 200 & 100 & 1350 \\
\hline $\mathrm{a}_{5}$ & 600 & 100 & 100 & $\infty$ & 0 \\
\hline$a_{6}$ & 2200 & 450 & 500 & 0 & $\infty$ \\
\hline $\mathrm{a}_{7}$ & $\infty$ & 500 & 500 & 500 & 550 \\
\hline
\end{tabular}

\begin{tabular}{|c|c|c|c|c|c|}
\hline & $a_{2}$ & $\mathrm{a}_{3}$ & $\mathrm{a}_{4}$ & $a_{5}$ & $\mathrm{a}_{6}$ \\
\hline a & 0 & $\overline{0}$ & $\infty$ & 5250 & 50 \\
\hline$a_{3}$ & 1400 & $\infty$ & $\mathbf{0}$ & $\mathbf{0}$ & 1250 \\
\hline$a$ & 600 & 100 & 0 & $\infty$ & 0 \\
\hline$a_{6}$ & 2200 & 450 & 400 & $\mathbf{0}$ & $\infty$ \\
\hline $\mathrm{a}_{7}$ & $\infty$ & 450 & 350 & $\mathbf{0}$ & 500 \\
\hline
\end{tabular}

Fig.7 - Matrixes of thermoeconomical expenditures $\mathbf{M}_{8}-\mathbf{M}_{11}$

\begin{tabular}{|c|c|c|c|c|c|}
\hline & $\mathrm{a}_{1}$ & $\mathrm{a}_{2}$ & $\mathrm{a}_{4}$ & $\mathrm{a}_{6}$ & $a_{7}$ \\
\hline$a_{1}$ & $\infty$ & $\mathbf{0}$ & 50 & 50 & $\mathbf{8 5 0}$ \\
\hline$a_{2}$ & $\mathbf{0}$ & $\infty$ & 1100 & 2100 & 0 \\
\hline$a_{5}$ & 5250 & 600 & 0 & 0 & 150 \\
\hline$a_{6}$ & 50 & 2200 & 400 & $\infty$ & 650 \\
\hline$a_{7}$ & 750 & 0 & 400 & $\mathbf{5 5 0}$ & $\infty$ \\
\hline
\end{tabular}

\begin{tabular}{|c|c|c|c|c|c|}
\hline & $\mathrm{a}_{1}$ & $\mathrm{a}_{2}$ & $\mathrm{a}_{4}$ & $a_{6}$ & $\mathrm{a}_{7}$ \\
\hline $\mathrm{a}_{1}$ & $\infty$ & 0 & 50 & 50 & 850 \\
\hline a2 & 0 & $\infty$ & 1100 & 2100 & 0 \\
\hline$a_{5}$ & 5250 & 600 & 0 & 0 & 150 \\
\hline$a_{6}$ & 0 & 2150 & 350 & $\infty$ & 600 \\
\hline$a_{7}$ & 750 & 0 & 400 & $\mathbf{5 5 0}$ & $\infty$ \\
\hline
\end{tabular}

\begin{tabular}{c|c|c|c|c|}
\multicolumn{1}{c}{} & \multicolumn{2}{c}{$\mathrm{a}_{1}$} & $\mathrm{a}_{4}$ & \multicolumn{2}{c}{$\mathrm{a}_{6}$} & $\mathrm{a}_{7}$ \\
\cline { 2 - 5 } $\mathrm{a}_{1}$ & $\infty$ & $\mathbf{0}$ & $\mathbf{0}$ & $\mathbf{8 5 0}$ \\
\cline { 2 - 5 } $\mathrm{a}_{2}$ & $\mathbf{0}$ & $\mathbf{1 1 0 0}$ & $\mathbf{2 1 0 0}$ & $\infty$ \\
$\mathrm{a}_{5}$ & $\mathbf{5 2 5 0}$ & $\mathbf{0}$ & $\mathbf{0}$ & $\mathbf{0}$ \\
\cline { 2 - 5 } $\mathrm{a}_{6}$ & $\mathbf{0}$ & $\mathbf{3 5 0}$ & $\infty$ & $\mathbf{4 5 0}$ \\
\cline { 2 - 5 } & & & &
\end{tabular}

\begin{tabular}{|c|c|c|c|c|}
\hline & $a_{3}$ & $\mathrm{a}_{4}$ & $a_{5}$ & $\mathrm{a}_{6}$ \\
\hline$a_{3}$ & $\infty$ & $\mathbf{0}$ & 0 & 1250 \\
\hline$a_{5}$ & 100 & 0 & $\infty$ & 0 \\
\hline$a_{6}$ & 450 & 400 & 0 & $\infty$ \\
\hline$a_{7}$ & 450 & 350 & $\mathbf{0}$ & 500 \\
\hline & $\mathrm{a}_{3}$ & $\mathrm{a}_{4}$ & $a_{5}$ & $\mathrm{a}_{6}$ \\
\hline$a_{3}$ & $\infty$ & $\mathbf{0}$ & $\mathbf{0}$ & 1250 \\
\hline$a_{5}$ & $\mathbf{0}$ & 0 & $\infty$ & 0 \\
\hline $\mathrm{a}_{6}$ & 350 & 400 & $\mathbf{0}$ & $\infty$ \\
\hline$a_{7}$ & 350 & 350 & 0 & 500 \\
\hline
\end{tabular}

Fig.8 - Matrixes of thermoeconomical expenditures $\mathbf{M}_{12}-\mathbf{M}_{1}$. 
$\mathrm{a}_{3}$

\begin{tabular}{|c|c|c|}
\multicolumn{1}{c}{$\mathrm{a}_{3}$} & $\mathrm{a}_{4}$ & $\mathrm{a}_{5}$ \\
\hline$\infty$ & $\mathbf{0}$ & $\mathbf{0}$ \\
\hline $\mathbf{3 5 0}$ & $\mathbf{4 0 0}$ & $\mathbf{0}$ \\
\hline $\mathbf{3 5 0}$ & $\mathbf{3 5 0}$ & $\mathbf{0}$ \\
\hline
\end{tabular}

$\mathrm{a}_{3}$

\begin{tabular}{|c|c|c|}
\multicolumn{1}{c}{$\mathrm{a}_{3}$} & $\mathrm{a}_{4}$ & $\mathrm{a}_{5}$ \\
\hline $\boldsymbol{\infty}$ & $\mathbf{0}$ & $\mathbf{0}$ \\
\hline $\mathbf{0}$ & $\mathbf{4 0 0}$ & $\mathbf{0}$ \\
\hline $\mathbf{0}$ & $\mathbf{3 5 0}$ & $\mathbf{0}$ \\
\hline
\end{tabular}

\begin{tabular}{c|c|c|c|}
\multicolumn{1}{c}{} & \multicolumn{2}{c}{$\mathrm{a}_{4}$} & \multicolumn{2}{c}{$\mathrm{a}_{6}$} & \multicolumn{1}{c}{$\mathrm{a}_{7}$} \\
\cline { 2 - 4 } $\mathrm{a}_{1}$ & $\mathbf{0}$ & $\mathbf{0}$ & $\mathbf{8 5 0}$ \\
\cline { 2 - 4 } $\mathrm{a}_{5}$ & $\mathbf{0}$ & $\mathbf{0}$ & $\mathbf{0}$ \\
\cline { 2 - 4 } $\mathrm{a}_{6}$ & $\mathbf{3 5 0}$ & $\infty$ & $\mathbf{4 5 0}$ \\
\cline { 2 - 4 } & &
\end{tabular}

\begin{tabular}{|c|c|c|c|}
\hline & $a_{4}$ & $\mathrm{a}_{6}$ & $a_{7}$ \\
\hline$a_{1}$ & 0 & 0 & 850 \\
\hline$a_{5}$ & 0 & 0 & 0 \\
\hline $\mathrm{a}_{6}$ & 0 & $\infty$ & 100 \\
\hline
\end{tabular}

$\mathrm{a}_{1}$

\begin{tabular}{c|c|c|}
\multicolumn{1}{c}{$\mathrm{a}_{4}$} & \multicolumn{1}{c}{$\mathrm{a}_{6}$} \\
\cline { 2 - 3 } & $\mathbf{0}$ & $\mathbf{0}$ \\
\cline { 2 - 3 } & $\mathbf{0}$ & $\infty$ \\
\hline
\end{tabular}

$\mathrm{a}_{6} \mathrm{a}_{4}$

Fig.9 - Matrixes of

thermoeconomical expenditures $M_{18}-M_{23}$.

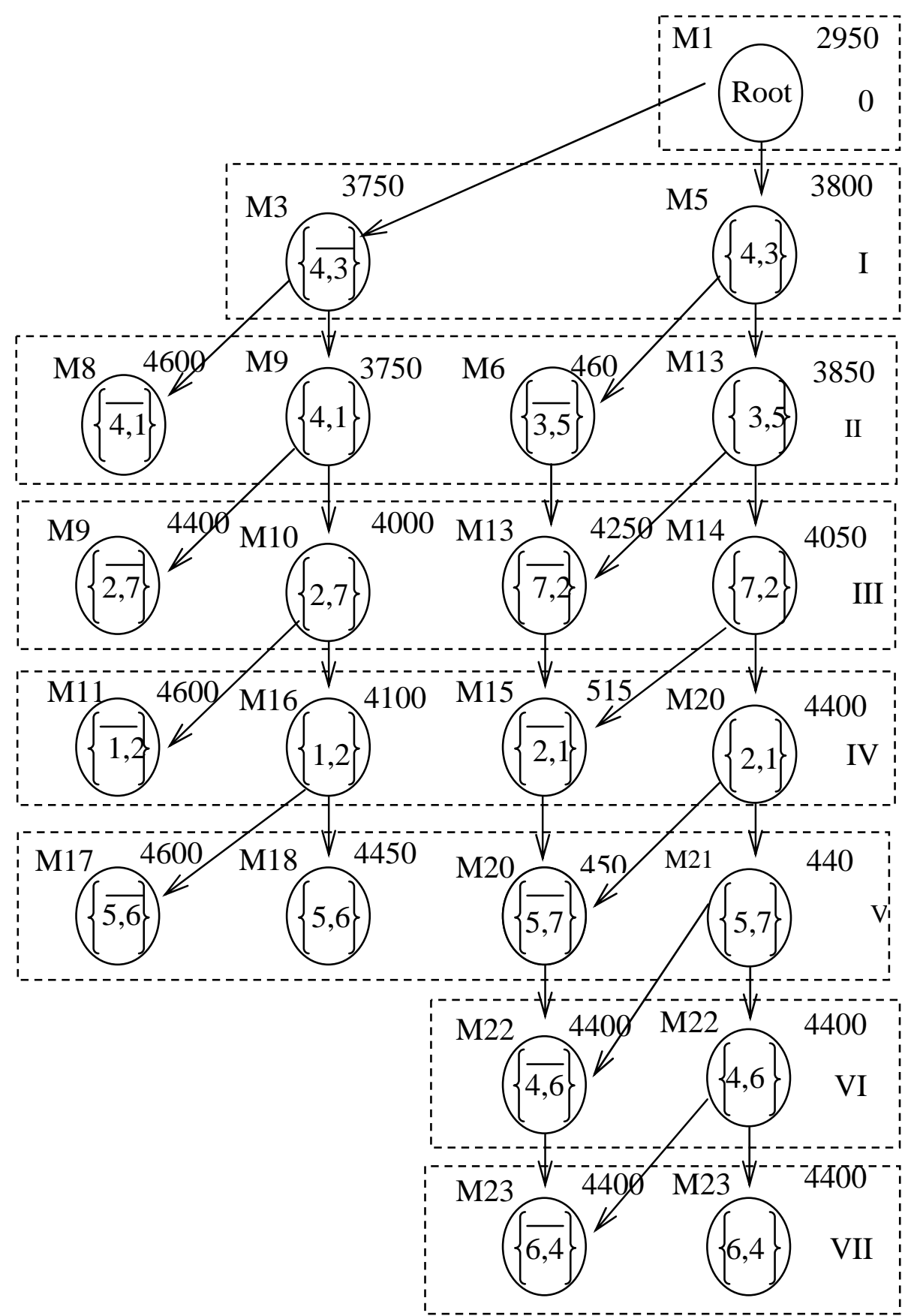

Fig.10 - Tree of thermoeconomical expenditure. 


\section{CONCLUSION}

The problem of optimisation for CNES has to be solved separately from the problem of optimisation of other energy intensive systems. On the basis of the unique features of such a system, it is possible to build an effective procedure for optimisation.

In this paper, the authors develop and analyse a graph of thermoeconomical expenditure through a unique approach. The suggested method and algorithm are based on seeking a Hamilton contour in the graph of thermoeconomical expenditure.

The method is illustrated with a numerical example of a single contour CNES of a city with seven regions of energy consumption.

\section{REFERENCES}

[1] Bejan, A., Tsatsaronis, G., Moran, M., Thermal Design and Optimization, John Wiley \& Sons Inc., New York, 1996.

[2] E. Sciubba, R. Melli, Artificial Intellegence in Thermal Systems Design: Consept and Applications, Nova Science Pub., 1998

[3] E Sciubba, "Beyond thermoeconomics? The concept of Extended Exergy Accounting and its application to the analysis and design of thermal systems", Exergy- an International Journal, 2001, Vol.1, pp. 68-85.

[4] Erlach B., Tsatsaronis G., Cziesla F., "A new approach for assigning cost and fuels to cogeneration products”, Proc. of International Conference ECOS-01, Istanbul, Turkey, 2001, pp.107-115.

[5] Casarosa C., Franco A., "Thermodynamic optimization of the operative parameters for the heat recovery in combined power plants", Int. Journal of pplied Thermodynamics Vol.4, N1, 2001, pp.43- 52

[6] Cornelissen, R.L., van Nimwegen, P.A., Hirs, G.G., ” Exergetic life cycle analysis”, Proc. of International Conference ECOS-2000, Twente, Netherlands, 2000, pp.1131-1143.

[7] Nikulshin, V., Wu, C.,“ Thermodynamic analysis of energy intensive systems on exergy topological models”, Proc.of 12-Th. International Symposium on transport phenomena, ISTP-12, Istanbul, Turkey, 2000, pp. 341-349.

[8] Nikulshin, V., Wu, C., "Thermodynamic analysis of energy intensive systems based on exergy- topological models", Exergy-an International Journal, 2001, Vol.1, pp. 173180.

[9] Nukulshin V., Wu C., Nikulshina V., "Exergy efficiency calculation of energy intensive systems by graphs", Proc. of International
Conference ECOS- 01, Istanbul, Turkey, 2001, pp.107-115.

[10] Nikulshin, V., Wu, C., "Method of thermodynamic analysis and optimization of energy intensive systems on exergy flow graphs”, Proc. ofInternational Conference on Power and Energy Systems, Las Vegas, Nevada, USA, 1999, pp.489- 491.

[11] Wu, C., Nikulshin, V., "Method of thermoeconomical optimization of energy intensive stems with linear structure on graphs", Iternational Journal of Energy Research, 24, 2000, pp.615-623.

[12] Nikulshin V., Wu C., Bailey M., Nikulshina V., "Method of thermoeconomical optimization on graphs of energy intensive systems with pair interplay of flows”, Proc. of International Conference ECOS-02, Berlin, Germany, 2002, p.1477-1484.

[13] Harary F., Graph Theory. Narosa Publishing House, New Deli, 1995.

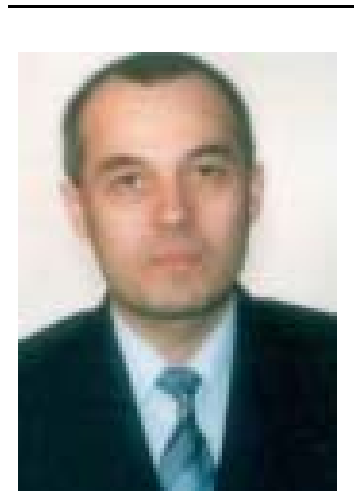

Vladimir Nikulshin is a Professor and Head of Theoretical General and Nonconventional Power Engineering Department of the Odessa National Polytechnic University, author of new exergytopological method of thermodynamic analysis and optimization of energy intensive systems.

Fundamentals of the theory and method are published in 158 scientific papers, 6 monographs, 6 scientific and technical reports. Published 32 papers on teaching and methods including 3 teaching aids. $\mathrm{He}$ is Academician of International Academy of Refrigeration, member of Scientific Boards: "International Centre of Applied Thermodynamic", "Pacific Centre for Thermal-Fluids Engineering", "Ministry Education and Science of Ukraine in speciality".

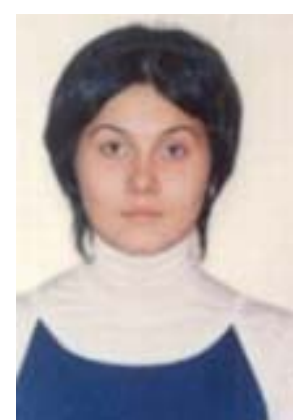

Viktoria von Zedtwitz obtained her second Master's degree in 2005 from Stockholm Royal Institute of Technology and the first Master's degree in 2003 from Odessa State Academy of Refrigeration. She has 23 published scientific Paper. Currently she is a PhD student of Swiss Federal Institute of Technology (Zurich). Her main area of interest is applied thermodynamics as well as renewable energy sources. 